University of Wollongong

Research Online

Faculty of Engineering and Information

Faculty of Engineering and Information

Sciences - Papers: Part B

Sciences

2016

Smart design of hollow AuPt nanospheres with a porous shell as superior electrocatalysts for ethylene glycol oxidation

Qingqing Lu

Chinese Academy Of Sciences

Changting Wei

Chinese Academy of Sciences

Litai Sun

Chinese Academy of Sciences

Zeid A. Al Othman

King Saud University

Victor Malgras

National Institute for Materials Science, Japan, vm961@uowmail.edu.au

See next page for additional authors

Follow this and additional works at: https://ro.uow.edu.au/eispapers1

Part of the Engineering Commons, and the Science and Technology Studies Commons

Research Online is the open access institutional repository for the University of Wollongong. For further information contact the UOW Library: research-pubs@uow.edu.au 


\title{
Smart design of hollow AuPt nanospheres with a porous shell as superior electrocatalysts for ethylene glycol oxidation
}

\author{
Abstract \\ Hollow bimetallic electrocatalysts have recently stimulated increasing attention due to their accessible \\ interior surface and bimetallic synergetic effect. Herein, for the first time, we successfully anchor a \\ porous AuPt shell on modified silica spheres with the assistance of Pluronic F127. The whole process \\ consists of simple ultrasonic mixing for $30 \mathrm{~min}$ at room temperature without any organic solvent. After \\ metal deposition and silica etching, well-defined hollow structures are obtained in high yield. The hollow \\ spheres are further characterized by scanning electron microscopy and transmission electron \\ microscopy. The electrochemical analysis reveals that the as-prepared samples demonstrate superior \\ electrocatalytic activity and durability relative to the commercial $\mathrm{Pt} / \mathrm{C}$ catalyst, showcasing the potential \\ of these AuPt hollow spheres as electrocatalysts for ethylene glycol oxidation in an alkaline medium.

\section{Disciplines} \\ Engineering | Science and Technology Studies

\section{Publication Details} \\ Lu, Q., Wei, C., Sun, L., Al Othman, Z. A., Malgras, V., Yamauchi, Y., Wang, H. \& Wang, L. (2016). Smart \\ design of hollow AuPt nanospheres with a porous shell as superior electrocatalysts for ethylene glycol \\ oxidation. RSC Advances: an international journal to further the chemical sciences, 6 (23), 19632-19637.
}

\section{Authors}

Qingqing Lu, Changting Wei, Litai Sun, Zeid A. Al Othman, Victor Malgras, Yusuke Yamauchi, Hongjing Wang, and Liang Wang 


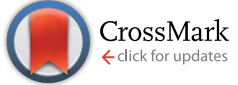

Cite this: RSC Adv., 2016, 6, 19632

\title{
Smart design of hollow AuPt nanospheres with a porous shell as superior electrocatalysts for ethylene glycol oxidation $\uparrow$
}

\author{
Qingqing Lu, ${ }^{\text {ab }}$ Changting Wei, ${ }^{\text {ab }}$ Litai Sun, ${ }^{\text {ab }}$ Zeid A. ALOthman, ${ }^{c}$ Victor Malgras, ${ }^{d}$ \\ Yusuke Yamauchi, ${ }^{\text {cd }}$ Hongjing Wang*e and Liang Wang*ae
}

\begin{abstract}
Hollow bimetallic electrocatalysts have recently stimulated increasing attention due to their accessible interior surface and bimetallic synergetic effect. Herein, for the first time, we successfully anchor a porous AuPt shell on modified silica spheres with the assistance of Pluronic F127. The whole process consists of simple ultrasonic mixing for $30 \mathrm{~min}$ at room temperature without any organic solvent. After metal deposition and silica etching, well-defined hollow structures are obtained in high yield. The hollow spheres are further characterized by scanning electron microscopy and transmission electron microscopy. The electrochemical analysis reveals that the as-prepared samples demonstrate superior electrocatalytic activity and durability relative to the commercial Pt/C catalyst, showcasing the potential of these AuPt hollow spheres as electrocatalysts for ethylene glycol oxidation in an alkaline medium.
\end{abstract}

Received 21st November 2015 Accepted 3rd February 2016

DOI: $10.1039 / \mathrm{c} 5 \mathrm{ra} 24709 \mathrm{~h}$

www.rsc.org/advances nanospheres, nanocages and nanotubes by reacting $\mathrm{Ag}$ nanospheres, nanocubes and nanowires with the appropriate salt precursors. However, AgCl precipitates inevitably, thus complicating the procedure and severely hindering the yield. ${ }^{\mathbf{1 6}}$ Hollow Pt-based nanospheres were also obtained by employing Co or Ni nanoparticles as sacrificial templates. This approach, however, requires nitrogen to protect the material from oxidation during the whole process., ${ }^{3,49}$ Recently hollow PtCuCo nanoparticles were synthesized by acetic acid-assisted chemical dealloying process. The initial template was obtained by mixing oleylamine, oleic acid and 1-octadecene at $230{ }^{\circ} \mathrm{C}$ for $30 \mathrm{~min} .{ }^{12}$ In all of the aforementioned systems, the required matrices sometimes produce undesirable by-products, making them unsuitable for commercial production at a large scale.

Silica templates can be used for the preparation of hollow structures. The production of monodispersed $\mathrm{SiO}_{2}$ spheres can be easily scaled up by a classical Stöber method. ${ }^{17}$ Silica materials are environmentally friendly and economically viable. ${ }^{18}$ Moreover, the hollow cavity can be precisely tuned by simply changing the size and the shape of the silica templates. ${ }^{\mathbf{1 9 - 2 1}}$

It is noteworthy that the tolerance and activity for Pt catalysts is limited by the formation of carbon monoxide (CO)-like intermediates. This hindrance can be efficiently overcome by partially substituting Pt with a secondary metal to benefit from an improved bimetallic electronic landscape. As a typical example, Zhang et al. revealed that Au clusters can protect the Pt electrocatalysts against dissolution during oxygen reduction reaction. ${ }^{22}$ Besides, adjacent $\mathrm{Au}$ can effectively oxidize $\mathrm{CO}$ species into $\mathrm{CO}_{2}$ and regenerate the poisoned surfaces during methanol oxidation reaction. ${ }^{23}$
State Key Laboratory of Electroanalytical Chemistry, Changchun Institute of Chemistry, Chinese Academy of Sciences, Changchun, Jilin 130022, P. R. China E-mail: wangliang@zjut.edu.cn

${ }^{b}$ University of Chinese Academy of Sciences, Beijing 100039, P. R. China ${ }^{c}$ Department of Chemistry, College of Science, King Saud University, Riyadh 11451, Saudi Arabia

${ }^{d}$ International Center for Materials Nanoarchitectonics (MANA), National Institute for Materials Science (NIMS), 1-1 Namiki, Tsukuba, Ibaraki 305-0044, Japan

${ }^{e}$ College of Chemical Engineering, Zhejiang University of Technology, Hangzhou, Zhejiang 310014, P. R. China. E-mail: hjw@zjut.edu.cn

$\dagger$ Electronic supplementary information (ESI) available. See DOI: 10.1039/c5ra24709h 
Here we propose an efficient route to obtain uniformly sized AuPt hollow nanospheres (AuPt-HNSs) with porous shell via a silica-templated process using F127 as surfactant and poredirecting agent, and ascorbic acid as soft reducing agent. Through the porous shells, the guest species are allowed to access the inner active sites, and consequently enhance their catalytic performance. ${ }^{24}$ Our synthetic process does not contain any organic solvent and can be successfully achieved through a one-step bimetallic decoration of porous AuPt shell on the surface of silica spheres at room temperature. After removing the template, the as-prepared AuPt-HNSs demonstrate superior electrocatalytic activity and durability relative to the commercial $\mathrm{Pt} / \mathrm{C}$ catalyst toward ethylene glycol oxidation in alkaline medium.

\section{Experimental section}

\subsection{Materials and chemicals}

$\mathrm{HAuCl}_{4} \cdot 4 \mathrm{H}_{2} \mathrm{O}, \mathrm{K}_{2} \mathrm{PtCl}_{4}$, hydrofluoric acid (HF), $\mathrm{NH}_{3} \cdot \mathrm{H}_{2} \mathrm{O}$, isopropanol, ethylene glycol $\left(\mathrm{CH}_{2} \mathrm{OHCH}_{2} \mathrm{OH}\right)$, sodium hydroxide $(\mathrm{NaOH})$, tetraethyl orthosilicate (TEOS) and ascorbic acid (AA) were obtained from Sinopharm Chemical Reagent Co, Ltd (Shanghai, China). 3-Aminopropyltrimethoxysilane (APTMS) and Pluronic F127 $\left(\mathrm{PEO}_{100} \mathrm{PPO}_{65} \mathrm{PEO}_{100}\right)$ were purchased from Sigma. Commercial Pt/C catalyst was ordered from Alfa Aesar. The reagents were used without any further purification.

\subsection{Synthesis of $\mathrm{SiO}_{2}$ spheres}

Typically, $200 \mathrm{~mL}$ of ethanol was mixed with $15.2 \mathrm{~mL}$ of $\mathrm{H}_{2} \mathrm{O}$ and $6.4 \mathrm{~mL}$ of $\mathrm{NH}_{3} \cdot \mathrm{H}_{2} \mathrm{O}$, and the solution was stirred vigorously for $1 \mathrm{~h}$ at room temperature. Then, $12 \mathrm{~mL}$ of TEOS was injected into the above mixture. After 3 hours, the milky product was collected by centrifugation at $10000 \mathrm{rpm}$ for $10 \mathrm{~min}$, followed by washing with ethanol and water. The product was finally dried at $50{ }^{\circ} \mathrm{C}$.

\subsection{Synthesis of AuPt-HNSs}

Firstly, the surface of silica spheres was modified with amino group. $150 \mathrm{mg}$ of silica particles was dissolved in a mixture of $45 \mathrm{~mL}$ of isopropanol and $900 \mu \mathrm{L}$ of APTMS. Then the suspension was refluxed at $353 \mathrm{~K}$ for $10 \mathrm{~h}$. The functionalized $\mathrm{SiO}_{2}$ spheres were collected by centrifugation and washed thoroughly with ethanol and water, and then dried at $323 \mathrm{~K}$. Secondly, $2.0 \mathrm{mg}$ of the functionalized silica spheres was dispersed in a solution of $\mathrm{K}_{2} \mathrm{PtCl}_{4}(1.5 \mathrm{~mL}, 20 \mathrm{mM})$ and $\mathrm{HAuCl}_{4} \cdot 4 \mathrm{H}_{2} \mathrm{O}(0.5 \mathrm{~mL}, 20 \mathrm{mM})$. After dissolving $20 \mathrm{mg}$ F127, AA $(2.0 \mathrm{~mL}, 0.1 \mathrm{M})$ was added and the mixture was sonicated for 30 min at room temperature. Finally, the obtained product was washed with water and dispersed in $10 \mathrm{wt} \% \mathrm{HF}(20 \mathrm{~mL})$ overnight. The as-prepared AuPt-HNSs were dried at $323 \mathrm{~K}$ before the electrochemical tests.

\subsection{Characterizations}

The morphology and surface structure were examined by a XL30 ESEM FEG scanning electron microscope (SEM) with an accelerating voltage of $20 \mathrm{kV}$. The transmission electron microscopy (TEM) and elemental analysis mapping were recorded on a JEM-2100F high-resolution transmission electron microscope operating at $200 \mathrm{kV}$. Nitrogen adsorption-desorption isotherms were obtained by using an automatic $\mathrm{N}_{2}$ adsorption-desorption instrument (Quantachrome Autosorb Automated Gas Sorption System) and the samples were degassed in vacuum at $323 \mathrm{~K}$ for $24 \mathrm{~h}$. X-ray photoelectron spectroscopy (XPS) measurements were performed on an ESCALAB-MKII spectrometer (VG Co, United Kingdom) with an $\mathrm{Al} \mathrm{K} \alpha \mathrm{X}$-ray radiation as the X-ray source for excitation. Electrochemical experiments were carried out with a $\mathrm{CHI} 842 \mathrm{c}$ electrochemical analyzer (Chenhua Co., Shanghai, China).

\subsection{Electrochemical measurements}

A conventional three electrode cell was used, including a platinum wire as counter electrode, a $\mathrm{Ag} / \mathrm{AgCl}(3 \mathrm{M} \mathrm{KCl})$ electrode as reference electrode and a modified glassy carbon electrode (GCE, $3 \mathrm{~mm}$ in diameter) as working electrode. The glassy carbon electrode was first polished with $\mathrm{Al}_{2} \mathrm{O}_{3}$ powder, washed with water and ethanol, and coated with the samples $(2 \mathrm{mg}$ $\left.\mathrm{mL}^{-1}, 3 \mu \mathrm{L}\right)$ and Nafion $(0.05 \mathrm{wt} \%, 3 \mu \mathrm{L})$. The Pt loading amount was $56.6 \mu \mathrm{g} \mathrm{cm}^{-2}$. Before electrochemical experiments, the catalyst surfaces were cleaned by cycling between $-0.2 \mathrm{~V}$ to $1.2 \mathrm{~V}$ (vs. $\mathrm{Ag} / \mathrm{AgCl}$ ) in $\mathrm{N}_{2}$ saturated $0.5 \mathrm{M} \mathrm{H}_{2} \mathrm{SO}_{4}$ solution. The electrochemically active surface areas (ECSAs) of Pt were estimated by integrating the charges involved in hydrogen desorption $\left(Q_{\mathrm{H}}\right)$, assuming $210 \mu \mathrm{C} \mathrm{cm}^{-2}$ as the monolayer desorption of hydrogen $\left(q_{\mathrm{H}}\right)$ at a scan rate of $50 \mathrm{mV} \mathrm{s}^{-1}$, following: $:^{25}$

$$
\mathrm{ECSA}=\frac{Q_{\mathrm{H}}}{m \times q_{\mathrm{H}}}
$$

where $m$ is the mass of Pt. Ethylene glycol oxidation measurements were performed in a mixture of $0.5 \mathrm{M} \mathrm{NaOH}$ and $0.5 \mathrm{M}$ $\mathrm{CH}_{2} \mathrm{OHCH}_{2} \mathrm{OH}$ between $-0.8 \mathrm{~V}$ and $0.4 \mathrm{~V}$ at a sweeping rate of $50 \mathrm{mV} \mathrm{s}^{-1}$. The chronoamperometric curves were obtained at $-0.1 \mathrm{~V}(v s$. $\mathrm{Ag} / \mathrm{AgCl}$ ) for $3600 \mathrm{~s}$. The current densities were acquired by normalizing with respect to the ECSA and the mass of Pt.

\section{Results and discussion}

As shown in Scheme 1, AuPt-HNSs are obtained by etching the $\mathrm{SiO}_{2}$ spheres decorated with a porous AuPt shell. In this work, the hard-template $\left(\mathrm{SiO}_{2}\right)$ is synthesized through a Stöber method. The well-dispersed $\mathrm{SiO}_{2}$ spheres have an average diameter of around $120 \mathrm{~nm}$ (Fig. S1 $\dagger$ ). They are subsequently

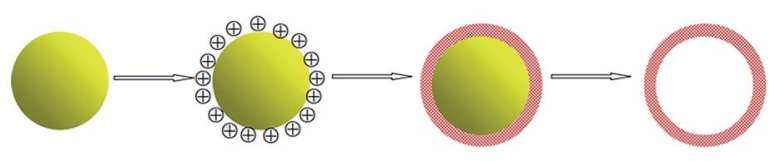

\section{$\mathrm{SiO}_{2} \quad$ modified $\mathrm{SiO}_{2} \quad \mathrm{SiO}_{2} / \mathrm{AuPt}$ AuPt-HNSs}

Scheme 1 Schematic illustration of the synthetic procedure of hollow AuPt nanospheres. 
functionalized with the amino groups of APTMS. Due to the electrostatic interaction between $-\mathrm{NH}_{2}{ }^{+}$and $\mathrm{AuCl}_{4}{ }^{-} / \mathrm{PtCl}_{4}{ }^{2-}$, the addition of reducing agent (AA) initiates the formation of $\mathrm{Au}-$ rich nuclei on the silica surface, thereby promoting the subsequent deposition of porous shells with the assistance of F127.

The surface morphology and structure of the obtained AuPtHNSs (after the removal of the $\mathrm{SiO}_{2}$ spheres) were investigated by scanning electron microscopy (SEM) and transmission electron microscopy (TEM). As revealed in Fig. 1A, monodispersed three-dimensional spheres are successfully obtained without any by-products. There are no serious cracks or collapses after the etching treatment, which confirms the effectiveness of this approach to obtain hollow structures.

The rough and dendritic surfaces indicate the existence of the porous shells. Pluronic F127 is a versatile structural directing agent used for the formation of nanoporous carbon and nanoporous/dendritic metals. ${ }^{13,19,20,24,26} \mathrm{~A}$ previous report has also demonstrated that AA is not only a common reducing agent but also favors the growth of branches. ${ }^{27}$ Guo et al. reported high-density $\mathrm{Au} / \mathrm{Pt}$ hybrid nanoparticles supported on silica nanospheres by mixing pre-synthesized Au nanoparticles and amino-functionalized silica spheres. Then, the obtained composites were further mixed with platinum precursors in a boiling solution for $30 \mathrm{~min} .^{28}$ Compared to the previous approach, our synthetic method does not require any presynthesized Au seed or high-temperature operation. We can successfully achieve the one-step bimetallic coverage of silica support in a short time at room temperature.

After the removal of the silica templates, clear cavities and a uniform particle size $(160 \mathrm{~nm} \pm 10 \mathrm{~nm})$ can be confirmed (Fig. 1B). The average wall thickness is about $20 \mathrm{~nm}$. The highresolution TEM (HRTEM) image of an individual particle shows the presence of well-defined dendritic shells (Fig. 2A) consisting of nanoparticles with a diameter of around $3 \mathrm{~nm}$. Random assembly of such nanoparticles form interconnected branches in all directions, showing the porous shells. The porous shell can allow the smooth diffusion of guest species and sufficient contact with inner reactive sites. Fig. 2B shows a high resolution TEM image of the rectangular area marked in Fig. 2A. The lattice distance is 0.23 $\mathrm{nm}$, which corresponds to the (111) plane of a face-centered cubic (fcc) AuPt crystal. Selected area electron diffraction (SAED) patterns confirm that the structure is polycrystalline, and the rings can be assigned to the (111), (200), (220), and (311) (Fig. S2†).

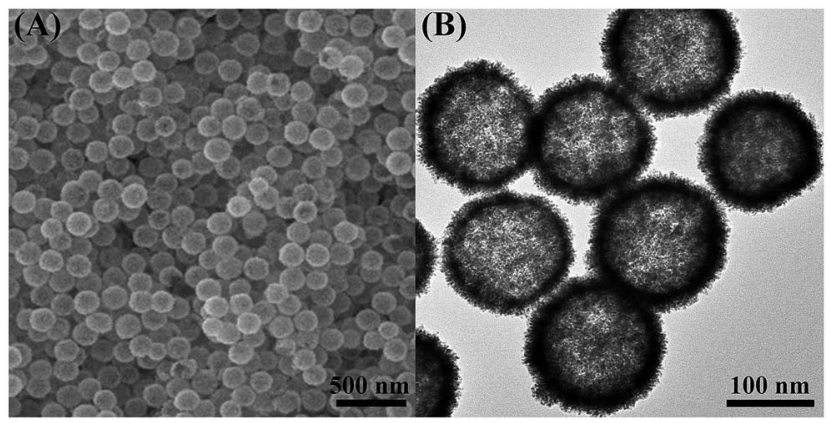

Fig. 1 (A) Typical SEM image and (B) TEM image of AuPt-HNSs.

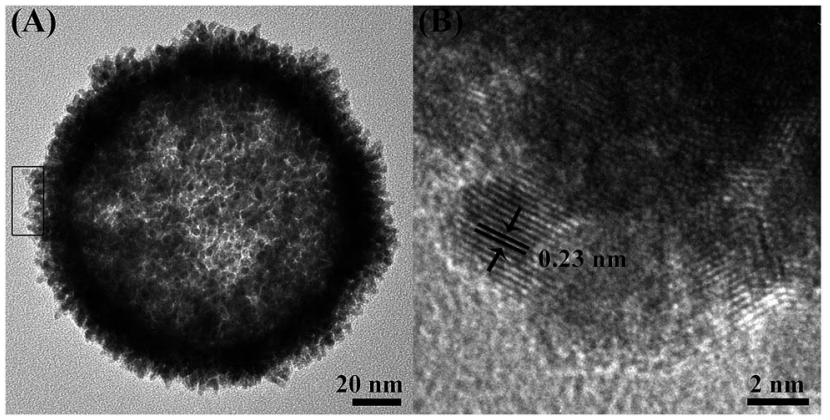

Fig. 2 (A) Highly magnified TEM image of an individual hollow AuPt nanoparticle. (B) HRTEM image of the selected region in panel (A).

The $\mathrm{N}_{2}$ adsorption-desorption isotherm shows a hysteresis loop at a relative pressure between 0.4 and 0.9 , which is characteristic of a porous structure (Fig. S3†). The BrunauerEmmett-Teller (BET) surface area of the AuPt-HNSs is calculated to be around $28.6 \mathrm{~m}^{2} \mathrm{~g}^{-1}$. This value is comparable with those of hyperbranched Pt nanostructure $\left(15 \mathrm{~m}^{2} \mathrm{~g}^{-1}\right),{ }^{27}$ PdPd alloy nanosponges $\left(19.04 \mathrm{~m}^{2} \mathrm{~g}^{-1}\right)^{29}$ and porous Pt nanoballs $\left(23 \mathrm{~m}^{2} \mathrm{~g}^{-1}\right) .^{30}$

High-angle annular dark field scanning transmission electron microscopy (HAADF-STEM) was further used to characterize this unique architecture. The inner cavities are distinguished by the sharp contrast between the shells and hollow interiors (Fig. 3A). Elemental mapping (Fig. 3B-D) reveals the presence of element $\mathrm{Au}$ and Pt. Considering the reduction potentials of $\mathrm{Pt}$ and $\mathrm{Au}$ species, it is expected that the outer surface is predominantly occupied by Pt atoms. However, the resolution of the system cannot reveal such spatial

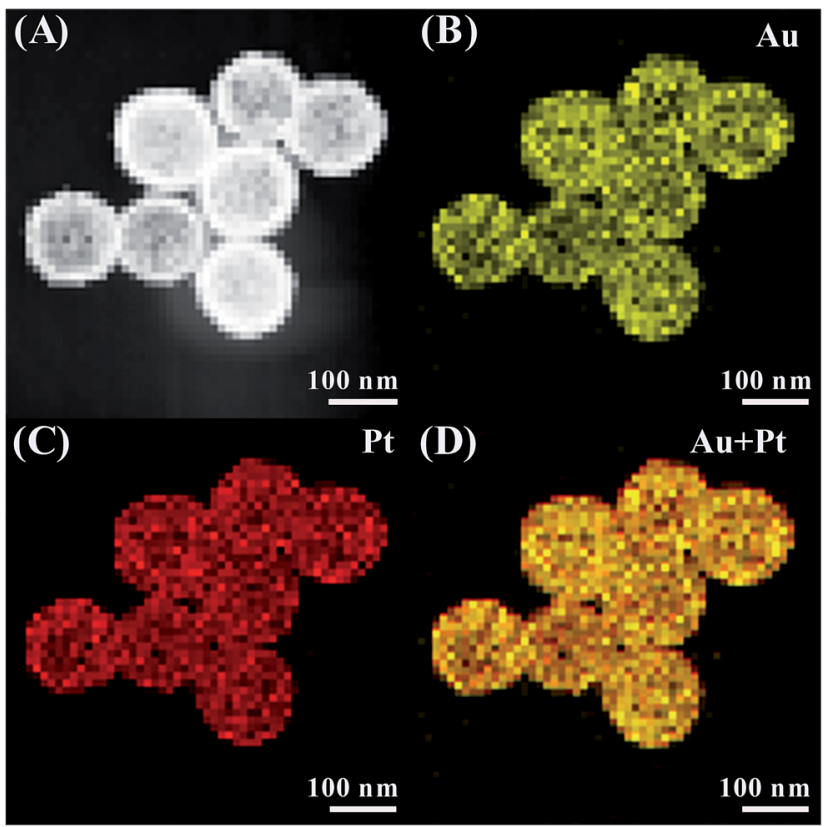

Fig. 3 (A) HAADF-STEM image and (B, C and D) corresponding elemental mapping of AuPt-HNSs. 
distribution on the elemental mapping. The $\mathrm{Au}$ : Pt atomic ratio is close to $1: 3$, which is also confirmed by ICP analysis.

X-ray photoelectron spectroscopy (XPS) was also adopted to measure the elemental composition and the surface chemical states. Fig. 4 shows the $\mathrm{Au} 4 \mathrm{f}$ and $\mathrm{Pt} 4 \mathrm{f}$ doublets. The peaks of $\mathrm{Au}$ $4 \mathrm{f}_{7 / 2}$ and $4 \mathrm{f}_{5 / 2}$ at 83.25 and $87.10 \mathrm{eV}$ are an indicator of the zerovalent state of Au. Similarly, the two peaks of Pt $4 \mathrm{f}_{7 / 2}(70.50$ $\mathrm{eV})$ and $\mathrm{Pt}_{4 \mathrm{f}_{5 / 2}}(73.75 \mathrm{eV})$ basically indicate the zerovalent state of Pt. No other visible peaks are present, which confirms the complete reduction of the metal species. ${ }^{\mathbf{8}, 31}$ The binding energies of $\mathrm{Pt} 4 \mathrm{f}_{7 / 2}$ and $\mathrm{Pt} 4 \mathrm{f}_{5 / 2}$ of AuPt-HNSs (Fig. 4) are shifted to lower values than those in commercial Pt/C catalyst (Fig. S4 $\dagger$ ), which is consistent with other reports. ${ }^{23,31}$ This shift implies the change in Pt electronic structure due to the formation of $\mathrm{Au}-\mathrm{Pt}$ bonds, which is partly responsible for enhancing the electrocatalytic performance.
It is well-known that XPS can provide the composition of the surface, while ICP results refer to the bulk composition. The $\mathrm{Pt}: \mathrm{Au}$ atomic ratio determined by XPS analysis is $91.6: 8.4$, which is much higher than the above ICP result. Since the reduction potential of $\mathrm{Au}(\mathrm{III})(+1.00 \mathrm{~V}$ vs. SHE) is much higher than $\mathrm{Pt}(\mathrm{II})(+0.76 \mathrm{~V} v s$. SHE), it is anticipated that $\mathrm{Au}$ will form on the silica surface prior to Pt, leaving a Pt-rich outer surface. ${ }^{\mathbf{2 4}}$

To evaluate the catalytic properties of the as-prepared sample, ethylene glycol (EG) oxidation was selected. For comparison, commercial $\mathrm{Pt} / \mathrm{C} \quad(3-5 \mathrm{~nm}$ Pt nanoparticles (20 wt\%) loaded on XC-72 carbon black) was also measured as a benchmark (Fig. S5 $\dagger$ ). Compared with methanol, direct ethylene glycol fuel cells (DEGFCs) exhibits notable advantages, such as a higher boiling point and a lower tendency to crossover from anode to cathode. ${ }^{\mathbf{9} 32-34}$ It has been previously testified that the kinetic rate of EG oxidation and the corrosion of materials can be greatly improved in alkaline medium, but the transfer
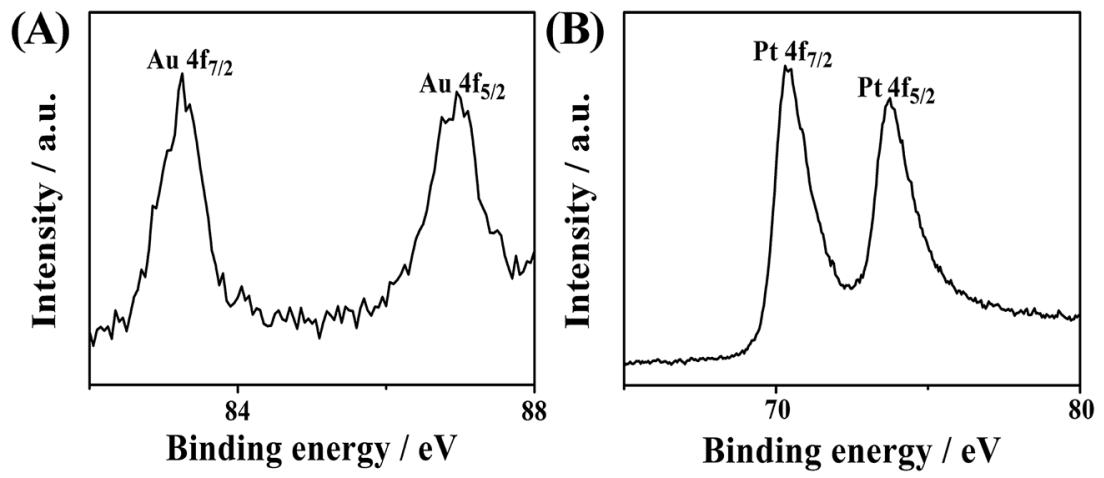

Fig. 4 (A) Au $4 f$ and (B) Pt $4 f$ XPS spectra of AuPt-HNSs.
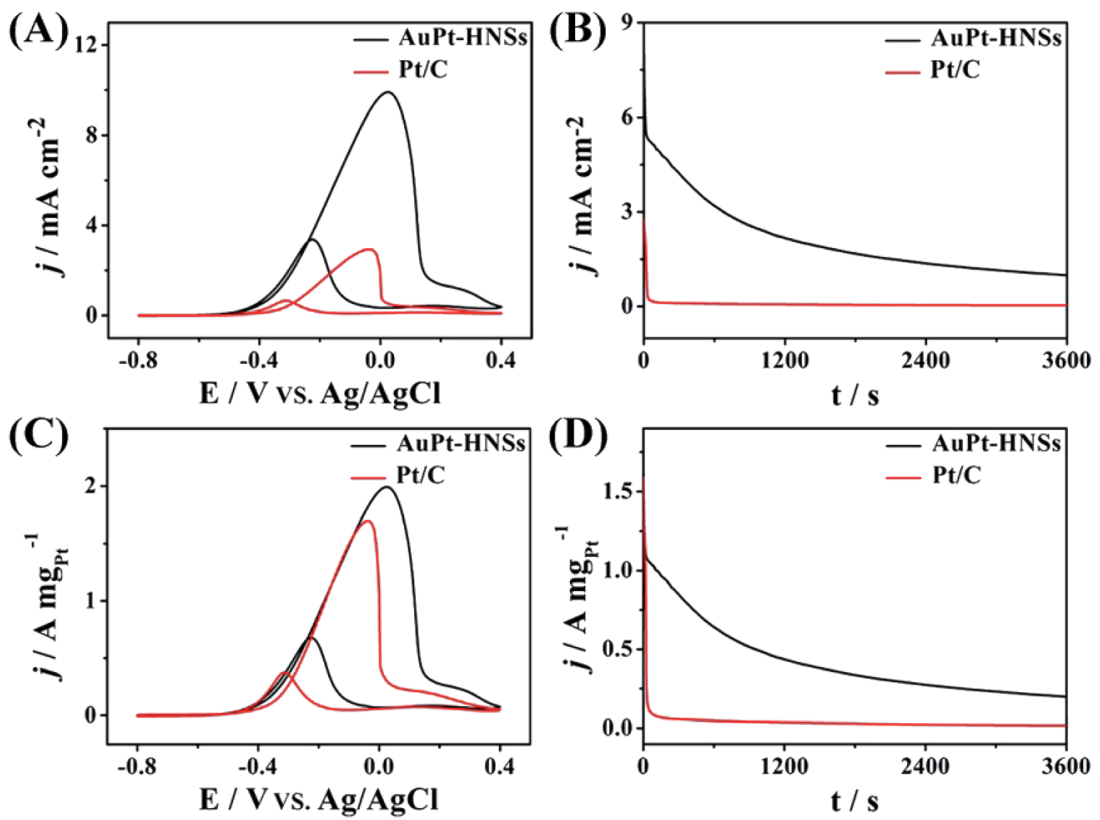

Fig. 5 ( $A$ and $C$ ) Cyclic voltammograms (CVs) and (B and $D)$ chronoamperometric curves of AuPt- HNSs and Pt/C in $0.5 \mathrm{M} \mathrm{NaOH}$ solution containing 0.5 M EG. The chronoamperometric curves were obtained at $-0.1 \mathrm{~V}$. 
efficiency remains a challenging limitation to overcome..$^{35}$ Thus it is still desirable to prepare efficient electrocatalysts for EG oxidation reaction. The specific electrochemical surface area (ECSA) of AuPt-HNSs is determined to be $20.1 \mathrm{~m}^{2} \mathrm{~g}^{-1}$ (Fig. S6 $\dagger$ ), which is higher than those of mesoporous $\mathrm{Pt}$ nanospheres (16.34 $\left.\mathrm{m}^{2} \mathrm{~g}^{-1}\right),^{36}$ PtAg nanotubes $\left(18.2 \mathrm{~m}^{2} \mathrm{~g}^{-1}\right){ }^{33}$ graphenebased porous Pt catalysts $\left(11.86 \mathrm{~m}^{2} \mathrm{~g}^{-1}\right),{ }^{37}$ and Pt nanowireSn@CNT $\left(17.2 \mathrm{~m}^{2} \mathrm{~g}^{-1}\right) .^{38}$

The surface specific activity (Fig. 5A) is a property intrinsic to a specific catalyst, whereas the mass specific activity (Fig. 5C) indicates the utilization efficiency during the catalytic reaction. ${ }^{39}$ In both cases, the typical EG oxidation cyclic voltammogram (CV) curves can be observed. The forward peak characteristic of the total oxidation for EG shows a higher current density ( $9.91 \mathrm{~mA} \mathrm{~cm}^{-2}$ ), which is 3.38 times higher than for $\mathrm{Pt} / \mathrm{C}\left(2.93 \mathrm{~mA} \mathrm{~cm}^{-2}\right)$. The mass activity of AuPt-HNSs is also higher than those of previously reported catalysts, as summarized in Table S1. $\dagger$ Although our AuPt-HNSs shows lower surface area compared to $\mathrm{Pt} / \mathrm{C}\left(57.9 \mathrm{~m}^{2} \mathrm{~g}^{-1}\right)$, the catalytic behavior of our sample toward EG oxidation exhibits an obvious advantage over the commercial $\mathrm{Pt} / \mathrm{C}$ catalyst.

In addition, the $I_{\mathrm{f}}: I_{\mathrm{b}}$ ratio $\left(I_{\mathrm{f}}\right.$ and $I_{\mathrm{b}}$ are forward and backward current densities, Fig. $5 \mathrm{C}$ ) is a strong indicator to evaluate the tolerance of a catalyst. The AuPt-HNSs have a higher ratio (2.97) than the hollow $\mathrm{Pt}_{54} \mathrm{Cu}_{23} \mathrm{Co}_{14}(2.5)^{9}$ or the Pt nanotubes (2.1). ${ }^{33}$ The current-time curves describe the tolerance of Ptbased catalysts to adsorbed carbonaceous intermediates during EG oxidation, as shown in Fig. 5B and D. At the early stage, all the current densities decay rapidly due to the accumulation of generated CO-like poisonous species. Both the starting and final current densities of AuPt-HNSs are superior to those of $\mathrm{Pt} / \mathrm{C}$, demonstrating an excellent tolerance over long periods of time.

After $3600 \mathrm{~s}$, the catalysts were measured in the same electrolyte. The AuPt-HNSs maintain $93.4 \%$ of its initial current (Fig. S7A and $\mathrm{C} \dagger$ ) while the commercial Pt/C lost $29 \%$ of its initial current (Fig. S7B and $\mathrm{D} \dagger$ ). Due to the smaller size of the Pt nanoparticle $(3-5 \mathrm{~nm})$, the $\mathrm{Pt} / \mathrm{C}$ exhibits a higher ECSA than that of the AuPt-HNSs. But, the small Pt nanoparticles in Pt/C are easily poisoned by the intermediate species adsorbed at the surface. From the above electrochemical results, it is concluded that the AuPt-HNSs shows promising potentials for future application in DEGFCs.

The improved electrocatalytic performance of the AuPt-HNSs possibly benefits from the following factors: (1) the porous shells are favorable for the diffusion of guest molecules, improving transport kinetics, (2) the hollow configuration can make the full use of the interior active sites and significantly increase the electrochemically active surface area, and (3) the synergistic effect between $\mathrm{Au}$ and $\mathrm{Pt}$ can contribute to high catalytic activity and good durability due to a better adsorption of hydroxyl groups and activation of poisoned surfaces..$^{22,23}$

\section{Conclusion}

Here we present an effective and facile method to synthesize AuPt-HNSs with porous shells in high yield, based on a one-step bimetallic decoration of functionalized $\mathrm{SiO}_{2}$ spheres with the assistance of F127 and AA. The whole process does not involve any organic solvent or high temperature. The AuPt-HNSs demonstrate superior catalytic activity and durability toward EG oxidation relative to the commercial $\mathrm{Pt} / \mathrm{C}$ in alkaline media. We strongly believe that our synthetic approach can be extended to prepare other Pt-based hollow electrocatalysts in the future.

\section{Acknowledgements}

This work was supported by the National Natural Science Foundation of China (no. 21273218). Z. A. A. extends his sincere appreciation to the Deanship of Scientific Research at King Saud University for funding the Prolific Research Group (PRG1436-04).

\section{References}

1 L. Au, X. Lu and Y. Xia, Adv. Mater., 2008, 20, 2517-2522.

2 E. Yan, Y. Ding, C. Chen, R. Li, Y. Hu and X. Jiang, Chem. Commun., 2009, 19, 2718-2720.

3 N. Liu, H. Han, Z. Yuan and Z. Ma, RSC Adv., 2015, 5, 18671872.

4 (a) J. Liu, Y. Wen, P. A. Aken, J. Maier and Y. Yu, Nano Lett., 2014, 14, 6387-6392; (b) J. Liu, Z. Yang, J. Wang, L. Gu, J. Maier and Y. Yu, Nano Energy, 2015, 16, 389-398; (c) J. Liu, P. Kopold, C. Wu, P. A. Aken, J. Maier and Y. Yu, Energy Environ. Sci., 2015, 8, 3531-3538.

5 (a) K. Eid, H. Wang, V. Malgras, Z. Alothman, Y. Yamauchi and L. Wang, J. Phys. Chem. C, 2015, 119, 19947-19953; (b) H. Wang, H. Jeong, M. Imura, L. Wang, L. Radhakrishnan, N. Fujita, T. Castle, O. Terasaki and Y. Yamauchi, J. Am. Chem. Soc., 2011, 133, 14526-14529.

6 X. Huang, Z. Zhao, L. Cao, Y. Chen, E. Zhu, Z. Lin, M. Li, A. Yan, A. Zettl, Y. M. Wang, X. Duan, T. Mueller and Y. Huang, Science, 2015, 348, 1230-1234.

7 (a) S. Park, D. Yoon, H. Baik and K. Lee, CrystEngComm, 2015, 17, 6852-6856; (b) H. Wang, S. Ishihara, K. Ariga and Y. Yamauchi, J. Am. Chem. Soc., 2012, 134, 10819-10821; (c) H. Wang, L. Wang, T. Sato, Y. Sakamoto, S. Tominaka, K. Miyasaka, N. Miyamoto, Y. Nemoto, O. Terasaki and Y. Yamauchi, Chem. Mater., 2012, 24, 1591-1598.

8 H. M. Song, D. H. Anjum, R. Sougrat, M. N. Hedhili and N. M. Khashab, J. Mater. Chem., 2012, 22, 25003-25010.

9 W. Hong, C. Shang, J. Wang and E. Wang, Nanoscale, 2015, 7, 9985-9989.

10 S. Guo, Y. Fang, S. Dong and E. Wang, J. Phys. Chem. C, 2007, 111, 17104-17109.

11 L. Dubau, J. Durst, F. Maillard, L. Guétaz, M. Chatenet, J. André and E. Rossinot, Electrochim. Acta, 2011, 56, 10658-10667.

12 X.-J. Liu, C.-H. Cui, H.-H. Li, Y. Lei, T.-T. Zhuang, M. Sun, M. N. Arshad, H. A. Albar, T. R. Sobahi and S.-H. Yu, Chem. Sci., 2015, 6, 3038-3043.

13 L. Wang and Y. Yamauchi, J. Am. Chem. Soc., 2013, 135, 16762-16765. 
14 F. Bai, Z. Sun, H. Wu, R. E. Haddad, X. Xiao and H. Fan, Nano Lett., 2011, 11, 3759-3762.

15 N. Fan, Y. Yang, W. Wang, L. Zhang, W. Chen, C. Zou and S. Huang, ACS Nano, 2012, 6, 4072-4082.

16 (a) Y. Sun, B. T. Mayers and Y. Xia, Nano Lett., 2002, 2, 481485; (b) W. Zhang, J. Yang and X. Lu, ACS Nano, 2012, 6, 7397-7405.

17 M. Yang, Q. Cai, C. Liu, R. Wu, D. Sun, Y. Chen, Y. Tang and T. Lu, J. Mater. Chem. A, 2014, 2, 13738-13743.

18 P. Kundu, H. Heidari, S. Bals, N. Ravishankar and G. V. Tendeloo, Angew. Chem., Int. Ed., 2014, 53, 3970-3974.

19 H. Ataee-Esfahani, Y. Nemoto, L. Wang and Y. Yamauchi, Chem. Commun., 2011, 47, 3885-3887.

20 H. Ataee-Esfahani, J. Liu, M. Hu, N. Miyamoto, S. Tominaka, K. C. W. Wu and Y. Yamauchi, Small, 2013, 9, 1047-1051.

21 A. A. Melvin, V. S. Joshi, D. C. Poudyal, D. Khushalani and S. K. Haram, ACS Appl. Mater. Interfaces, 2015, 7, 6590-6595.

22 J. Zhang, K. Sasaki, E. Sutter and R. R. Adzic, Science, 2007, 315, 220-222.

23 (a) H.-P. Liang, T. G. J. Jones, N. S. Lawrence, L. Jiang and J. S. Barnard, J. Phys. Chem. C, 2008, 112, 4327-4332; (b) J. Zeng, J. Yang, J. Y. Lee and W. Zhou, J. Phys. Chem. B, 2006, 110, 24606-24611.

24 H. Ataee-Esfahani, L. Wang, Y. Nemoto and Y. Yamauchi, Chem. Mater., 2010, 22, 6310-6318.

25 W. Li and A. M. Lane, Electrochem. Commun., 2011, 13, 913916.

26 Y. Fang, D. Gu, Y. Zou, Z. Wu, F. Li, R. Che, Y. Deng, B. Tu and D. Zhao, Angew. Chem., Int. Ed., 2010, 49, 7987-7991.
27 L. Wang, C. Hu, Y. Nemoto, Y. Tateyama and Y. Yamauchi, Cryst. Growth Des., 2010, 10, 3454-3460.

28 S. Guo, J. Zhai, Y. Fang, S. Dong and E. Wang, Chem.-Asian J., 2008, 3, 1156-1162.

29 C. Zhu, S. Guo and S. Dong, Chem.-Eur. J., 2013, 19, 11041111.

30 G. Surendran, L. Ramos, B. Pansu, E. Prouzet, P. Beaunier, F. Audonnet and H. Remita, Chem. Mater., 2007, 19, 50455048.

31 C. Li, H. Wang and Y. Yamauchi, Chem.-Eur. J., 2013, 19, 2242-2246.

32 A. Serov and C. Kwak, Appl. Catal., B, 2010, 97, 1-12.

33 Y. Kim, H. Kim and W. B. Kim, Electrochem. Commun., 2014, 46, 36-39.

34 W. Hong, C. Shang, J. Wang and E. Wang, Energy Environ. Sci., 2015, 8, 2910-2915.

35 C. Jin, Y. Song and Z. Chen, Electrochim. Acta, 2009, 54, 41364140.

36 Y. Li, B. P. Bastakoti, V. Malgras, C. Li, J. Tang, J. H. Kim and Y. Yamauchi, Angew. Chem., Int. Ed., 2015, 54, 11073-11077.

37 L. Zhang, J.-J. Shao, W. Zhang, C. Zhang, X. Zheng, H. Du and Q.-H. Yang, J. Phys. Chem. C, 2014, 118, 25918-25923.

38 S. Sun, G. Zhang, D. Geng, Y. Chen, M. N. Banis, R. Li, M. Cai and X. Sun, Chem.-Eur. J., 2010, 16, 829-835.

39 R. Chetty, S. Kundu, W. Xia, M. Bron, W. Schuhmann, V. Chirila, W. Brandl, T. Reinecke and M. Muhler, Electrochim. Acta, 2009, 54, 4208-4215. 